\title{
Recursos genéticos, propiedad intelectual, reparto de beneficios...
}

\author{
Asha Sukhwani ${ }^{1}$
}

Sumario: I. INTRODUCCIÓN. II. SECTORES DE LA INDUSTRIA QUE UTILIZAN LA BIODIVERSIDAD. III. ESPECIES UTILIZADAS SEGÚN SECTORES. IV. SECTOR AGROALIMENTARIO Y ESPECIES CULTIVADAS. V. ESPECIES SILVESTRES $Y$ SU INTERÉS EN LA INDUSTRIA. VI. INTERÉS EN NUEVAS ESPECIES. VII. PATENTES Y LA COMERCIALIZACIÓN DE NUEVOS PRODUCTOS. VIII. LOS DERECHOS DE PROPIEDAD INTELECTUAL Y EL CDB. IX. DERECHOS DE PROPIEDAD INTELECTUAL. X. CONCESIÓN DE DERECHOS DE PROPIEDAD INTELECTUAL. XI. LAS MARCAS. XII. LAS PATENTES DE INVENCIÓN. XIII. DOCUMENTOS DE PATENTE. XIV. PROTECCIÓN DE INVENCIONES EN OTROS PAÍSES. XV. EL DOBLE PAPEL DE LAS PATENTES. 1. Patentes y biodiversidad. A) Especies y estrategias de protección en Biotecnología. B) Patentes de Biodiversidad. C) Especies y estrategias de protección en Biodiversidad. XVI. BIOPROSPECCIÓN. XVII. INVESTIGACIÓN DEL CÁNCER. XVIII. REPARTO DE BENEFICIOS. XIX. DEFINICIONES CONFUSAS PARA LOS USUARIOS. XX. DIVULGACIÓN DEL PAÍS DE ORIGEN EN LAS SOLICITUDES DE PATENTE. XXI. COSTES DE COMERCIALIZACIÓN. XXII. CONOCIMIENTOS TRADICIONALES. XXIII. CONSIDERACIONES FINALES.

\section{INTRODUCCIÓN}

Desde que el ser humano está sobre el planeta e inició sus actividades para sobrevivir, comenzó a usar la biodiversidad ya sea como alimento, medicinas, textiles, construcción, con fines ornamentales, para artesanía, etc.

Ahora bien, la biodiversidad no está presente por igual en todo el planeta. Así, su distribución es tal que está más extendida en los Trópicos y el Ecuador y menos en las zonas templadas y frías.

1 Bióloga y Examinadora de Patentes. Oficina Española de Patentes y Marcas. 
Esta distribución natural, acentuada por las actividades humanas como la industrialización que han contribuido a destruir la biodiversidad, ha generado un eje de distribución Norte-Sur, de forma que los países en desarrollo y menos industrializados de zonas tropicales y subtropicales son, en general, proveedores de recursos biológicos y genéticos para usuarios ubicados en países industrializados de zonas templadas y frías.

En efecto, los usuarios de países industrializados están interesados en la exploración de la biodiversidad en los países donde se encuentra, ya sea con fines científicos y taxonómicos, como las Universidades y Centros de Investigación, o con fines comerciales, como las Empresas Farmacéuticas, Cosméticas, Agroalimentarias, etc., cuyo objeto es comercializar nuevos productos y obtener beneficios.

Por otra parte, hay que tener en cuenta la distribución de cada especie. Hay especies que crecen en varios continentes, otras en varios países de un continente, otras tan sólo en una zona, por ejemplo, en la Amazonía (Uncaria tomentosa). Por último, hay especies que crecen sólo en un Archipiélago como las Islas Canarias (Canariothamnus palmensis, Dracaena draco, Salvia canariensis), o se encuentran exclusivamente en una isla como Madagascar (Cabucala madagascariensis) o en la isla de Socotra (Kalanchoe farinacea, Dracaena cinnabari).

Cuanto más extendida esté una especie menos problema de conservación supone su explotación, y viceversa, cuanto menos extendida más atención hay que prestar a su conservación.

Las especies más interesantes para los usuarios que investigan en productos innovadores son las especies endémicas de un país o de una isla. Si a esas especies se les encuentra una aplicación con fines comerciales tienen un mayor valor estratégico, en particular, para los proveedores.

\section{SECTORES DE LA INDUSTRIA QUE UTILIZAN LA BIODIVERSIDAD}

- Farmacéutico

- Cosméticos

- Medicinas botánicas

- Agroalimentario

- Biocombustibles

- Colorantes

- Otros

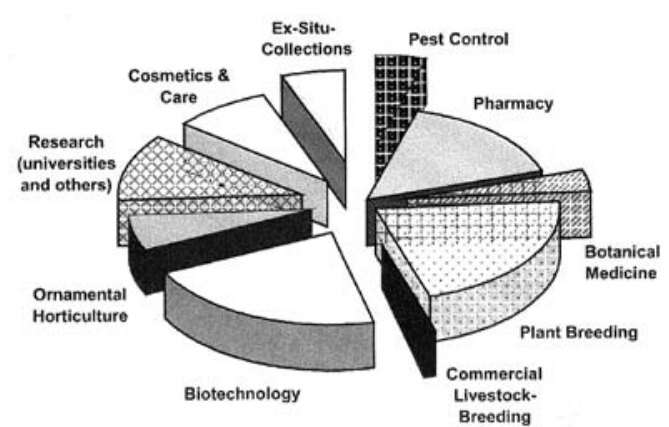

Karin Holm-Müller, Carmen Richerzhagen and Sabine Täuber: “Users of Genetic Resources in Germany. Awareness, Participation and Positions regarding the Convention on Biological Diversity”. BfN Federal Agency for Nature Conservation, 2005. 


\section{ESPECIES UTILIZADAS SEGÚN SECTORES}

El número de especies y la forma de utilización de éstas varía según los sectores. Hay especies de uso común en varios sectores de la industria como es el caso del Aloe vera que se utiliza tanto como alimento, en medicina y cosmética. Las especies habituales en alimentación como el trigo, la soja, el maíz, etc. son usadas, en algunos casos, de forma terapéutica y cosmética, así como biocombustibles.

Pero se podría decir que la mayoría de las especies utilizadas en el sector de medicinas botánicas, cosméticos y parte del farmacéutico no son de aplicación en el sector agroalimentario, como es el caso del Ginkgo biloba, Commiphora mukul, Mimosa tenuiflora, Kalanchoe farinacea, los tejos (Taxus spp.), musgos, líquenes, venenos de serpientes, ciertos invertebrados, etc.

\section{SECTOR AGROALIMENTARIO Y ESPECIES CULTIVADAS}

En general, y según datos de la FAO, el sector Agroalimentario ha utilizado de 7 a 8 mil especies a lo largo de la historia de la civilización humana.

Las especies aprovechadas que son cultivadas han sido sometidas a un proceso de mejora, a lo largo de siglos, gracias a la introducción de nuevos caracteres y genes, creándose variedades comestibles. El estudio del material genético es primordial en este sector.

Las especies silvestres no se suelen comer directamente. Sin embargo, las especies silvestres afines a las cultivadas resultan, a veces, muy útiles y preciadas en los programas de mejora. Un ejemplo, podría ser el teosinte, especie silvestre de donde procede el maíz.

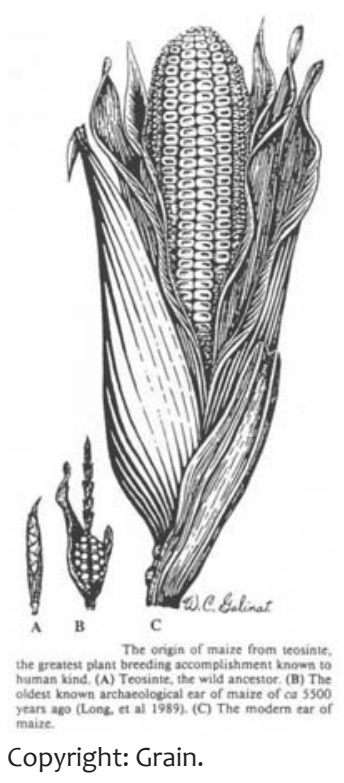

\section{ESPECIES SILVESTRES Y SU INTERÉS EN LA INDUSTRIA}

Al contrario que en el caso anterior, en los sectores que utilizan las especies con fines médicos o cosméticos son de mucha utilidad las especies silvestres, tal y como 
crecen en la naturaleza, e incluso si se cultivan, no son sometidas a programas de mejora genética.

En la Tabla 1 se recoge el número estimado de especies de plantas utilizadas con fines medicinales en los países asiáticos y en Estados Unidos². A esta cifra, de cerca de 53.000 especies, hay que añadir las especies utilizadas en otros continentes y, además, las especies utilizadas propiamente en el sector cosmético, que maneja anualmente gran cantidad de material de especies silvestres.

We recognize, however, that certain plant families have higher proportions of medicinal plants than others. Good examples are the Apocynaceae, Araliaceae, Apiaceae, Asclepiadaceae, Canellaceae, Guttiferae and Menispermaceae. In addition, these families are not distributed uniformly across the world. As a consequence, not only do some floras have higher proportions of medicinal plants than others, but also have certain plant families a higher proportion of threatened species than others (Table 9 in Appendix 1).

\section{TABLA 1}

How many plants are used medicinally world-wide?

\begin{tabular}{|c|c|c|c|}
\hline Country & Plant species & $\begin{array}{l}\text { Medicinal plant } \\
\text { species }\end{array}$ & $\%$ \\
\hline China & 26.092 & 4.941 & 18,9 \\
\hline India & 15.000 & 3.000 & 20,0 \\
\hline Indonesia & 22.500 & 1.000 & 4,4 \\
\hline Malaysia & 15.500 & 1.200 & 7,7 \\
\hline Nepal & 6.973 & 700 & 10,0 \\
\hline Pakistan & 4.950 & 300 & 6,1 \\
\hline Philippines & 8.931 & 850 & 9,5 \\
\hline Sri Lanka & 3.314 & 550 & 16,6 \\
\hline Thailand & 11.625 & 1.800 & 15,5 \\
\hline USA & 21.641 & 2.564 & 11,8 \\
\hline Viet Nam & 10.500 & 1.800 & 17,1 \\
\hline Average & 13.366 & 1.700 & 12,5 \\
\hline World & 422.000 & 52.885 & \\
\hline
\end{tabular}

Sources: Duke and Ayensu (1985); Govaerts (2001); Groombridge and Jenkins (1994, 2002); Jain and DeFiIlipps (1991); Moerman (1996); Padua et al. (1999).

$238 \quad 2$ ftp://ftp.fao.org/docrep/fao/o05/aa010e/AA010Eoo.pdf 
La estimación es que se han utilizado más de 70.000 especies en el conjunto de estos sectores, número muy superior al que utiliza el sector agroalimentario.

\section{INTERÉS EN NUEVAS ESPECIES}

El número de especies descritas está cifrada en algo más de 1.750.000 (UNEP, 1995) pero se considera que puede haber de 5 a 30 millones, tal vez unas 12 millones (WCMC, 1992). Cada año se descubren nuevas especies lo que hace que el interés por la biodiversidad no decaiga para todos los sectores de la industria que trabajan en ella.

Si se descubren o describen nuevas especies en selvas, bosques tropicales, fondos del mar, ambientes extremos (salinidad, altas temperaturas, metales, etc.) éstas podrían tener un potencial de aplicación en los sectores farmacéutico, cosmético y de fitomedicinas.

Para el sector agroalimentario, las especies de nueva descripción tienen menos provecho porque en este sector se requiere una mejora en el transcurso del tiempo para hacerlas comestibles o aumentar su valor nutritivo o comercial.

\section{PATENTES Y LA COMERCIALIZACIÓN DE NUEVOS PRODUCTOS}

Cuando un usuario encuentra una aplicación no descrita de una especie puede solicitar una patente. Esta es la práctica habitual de los usuarios de países industrializados como Estados Unidos, Canadá, Japón, Australia, Alemania, Inglaterra, Francia, España, etc. Gracias a ello, se han generado muchas patentes relacionadas con la biodiversidad.

Otros países como China, India, Corea también permiten proteger su biodiversidad o sus usos por el sistema de patentes, así como Méjico y Cuba. Pero la mayoría de los países de Iberoamérica no protegen por patente la biodiversidad, creándose una situación de protección desigual según la zona geográfica.

\section{Comercialización de Productos}
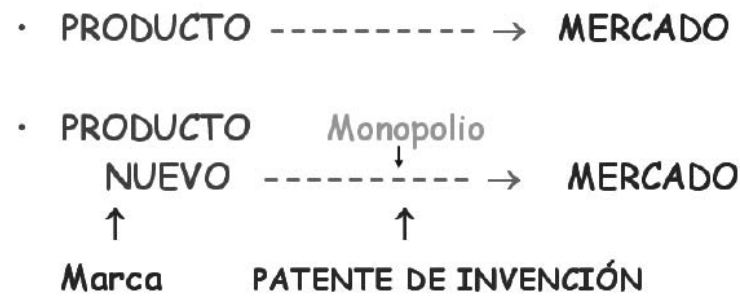
El objetivo de los usuarios que solicitan protección por propiedad industrial es comercializar productos nuevos con el beneficio del derecho exclusivo que otorgan las patentes y otros derechos de propiedad intelectual.

\section{LOS DERECHOS DE PROPIEDAD INTELECTUAL Y EL CDB}

El Convenio sobre Diversidad Biológica ha tenido en cuenta esta práctica habitual de los países industrializados, de proteger por patentes las tecnologías desarrolladas para procedimientos y productos nuevos, en su Artículo 16 que se refiere al "Acceso y Transferencia de Tecnología".

\section{Las Patentes y el Artículo 16 del CBD}

- ...En el caso de tecnología sujeta a patentes y otros derechos de propiedad intelectual, el acceso y la transferencia se harán asegurando la protección adecuada y eficaz de los derechos de propiedad intelectual (Art. 16-2).

- Cada país tomará medidas legislativas, administrativas o de política con objeto de que se asegure a los países en desarrollo, que aportan recursos genéticos, el acceso y la transferencia de tecnologías desarrolladas con esos recursos, incluidas las protegidas por patentes (Art. 16-3).

- Las Partes Contratantes, reconociendo que las patentes y otros derechos de propiedad intelectual pueden influir en la aplicación del presente Convenio, cooperarán a este respecto de conformidad con la legislación nacional y el derecho internacional para velar que esos derechos apoyen y no se opongan a los objetivos del presente Convenio (Art. 16-5).

El Artículo 16, párrafo 5 es el punto clave de la interacción entre patentes y otros derechos de propiedad intelectual y el $C D B$, de forma que reconociendo que las patentes pueden influir en la aplicación del Convenio, las Partes Contratantes "cooperarán ... para velar que esos derechos apoyen y no se opongan a los objetivos del presente Convenio".

Para comprender si es posible esta cooperación hay que entender bien cuál es el objeto de los "Derechos de Propiedad Intelectual”, quiénes son los titulares de estos derechos, quién los otorga y para qué se otorgan. Además, qué papel han desempeñado estos derechos en los países industrializados y en el proceso de transferencia de tecnología.

\section{DERECHOS DE PROPIEDAD INTELECTUAL}

Los Derechos de Propiedad Intelectual son derechos concedidos por una autori240 dad estatal con el fin de equilibrar dos objetivos: 
a) recompensar a los creadores por la innovación

b) aumentar el acervo científico, tecnológico y cultural de la sociedad

En los países industrializados se ha demostrado, desde el siglo XIX y a lo largo del siglo XX, que estos derechos han cumplido una función importante para aumentar las innovaciones en la sociedad industrial.

\section{Derechos de Propiedad Intelectual}

* Derechos de Autor (Copyright). Protegen trabajos literarios, artísticos o científicos. Libros, composiciones musicales, esculturas, pintura, fotografías, dibujos de ingeniería y programas de software para ordenadores.

* Derechos del Obtentor (Breeders' Rights). Derechos sui generis a VARIEDADES VEGETALES.

* Indicaciones Geográficas (Geographical Indications):

Denominaciones de Origen (Appellations of Origin). Protegen productos de zonas geográficas elaborados de una forma determinada y con control de calidad.

* Derechos de Propiedad Industrial:

- Invenciones: PATENTES DE INVENCIÓN Y MODELOS DE UTILIDAD

- Diseños Industriales: MOdelos (3D) y DiBujos Industriales (2D) (Forma y Configuración)

- Signos Distintivos: marcas comerciales (Productos y Servicios) (Palabras y Símbolos): NOMBRES COMERCIALES

\section{CONCESIÓN DE DERECHOS DE PROPIEDAD INTELECTUAL}

- La Autoridad que concede, en España, los Derechos de Autor (en inglés, “Copyright") es el Ministerio de Cultura.

- Los Derechos del Obtentor, las Denominaciones de Origen y las Indicaciones Geográficas los conceden el Ministerio de Agricultura.

- El Grupo más importante lo constituyen los "Derechos de Propiedad Industrial" para invenciones, diseños industriales y signos distintivos, cuyo objeto es proteger las innovaciones técnicas, las de diseño y las de identidad corporativa. En España, un Organismo Autónomo del Ministerio de Industria, la Oficina Española de Patentes y Marcas (OEPM) se encarga de la concesión de estos derechos entre los que cabe destacar los de Patentes y de Marcas. 


\section{LAS MARCAS}

Las marcas identifican un producto o un servicio en el mercado ("Aspirina", "Coca-Cola", "Volvo", "Sony”). Pueden ser denominativas, gráficas o mixtas.

La duración de la protección puede ser indefinida siempre que el titular renueve el derecho.

\section{LAS PATENTES DE INVENCIÓN}

La Patente es un título otorgado por el Estado por el que se reconoce un derecho exclusivo temporal sobre la invención protegida. Se considera "invención" una solución concreta nueva a un problema técnico determinado.

En general, no se consideran invenciones:

a) los descubrimientos, teorías científicas y métodos matemáticos.

b) obras literarias, estéticas y artísticas.

c) planes, reglas y métodos intelectuales, económico-comerciales o para juegos, o software.

d) formas de presentar información

e) métodos de diagnóstico, tratamiento quirúrgico o terapéutico aplicado al cuerpo humano o animal

La mayoría de las Leyes de Patentes de casi todos los países contemplan excepciones a la patentabilidad: no se consideran invenciones patentables las contrarias al orden público y a la moralidad, ni las variedades vegetales, razas animales o los procedimientos esencialmente biológicos para producir plantas y animales.

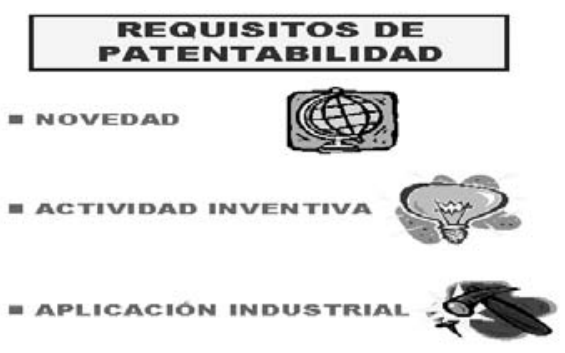

Para que una invención sea patentable tiene que cumplir con tres requisitos: novedad, actividad inventiva y aplicación industrial.

En la mayoría de las leyes de patente el solicitante es el que tiene derecho a la titularidad de la patente y puede ser una persona o varias personas físicas o una enti-

242 dad jurídica como una empresa, una universidad, etc. En países como Estados Uni- 
dos, el inventor es el que tiene derecho a la patente. También pueden darse distintos supuestos como coincidir el solicitante y el inventor, o existir una co-titularidad.

\section{Limitaciones al derecho exclusivo}

- Limitación temporal. La patente tiene una protección jurídica de 20 años desde la fecha de presentación, tras lo cual pasa a dominio público.

- Limitación geográfica. El derecho se circunscribe al territorio nacional del país donde se ha solicitado la protección (patente nacional) o en varios países (patente regional).

- Actos que no se consideran violación de los derechos:

* Utilización de la invención en el ámbito privado con fines no comerciales (uso privado).

* Experimentación científica (uso experimental)

* Producción de un medicamento en farmacia para ejecución de una receta médica.

El derecho exclusivo que otorga una patente es de $\mathbf{2 0}$ años, en la mayoría de los casos, pero requieren para mantener el derecho el pago de tasas anuales de mantenimiento, tasas que son crecientes. Tras este período, o si el solicitante no paga las tasas anuales, las patentes caen en dominio público y la tecnología descrita en el documento están disponible para su libre utilización a nivel comercial.

\section{Ámbito Geográfico de Protección}

- Patente Nacional: Se solicita en un país: España (ES), Francia (FR), Gran Bretaña (GB), Alemania (DE), Estados Unidos (US), China (CN), Japón (JP), Australia (AU), Nueva Zelanda (NZ), etc.

- Patente Regional: Solicitud para un conjunto de países: Patente Europea (30 países de Europa) se estableció en el Convenio sobre la Patente Europea (CPE) en Munich, en 1973. En África existen las patentes regionales administradas por ARIPO (inglés) y por OAPI (francés).

- Patente Internacional: Sistema PCT (Patent Cooperation Treaty) permite solicitar protección para una invención en cada uno de los Estados partes (actualmente 184 países) mediante una única solicitud internacional. No se trata de un procedimiento de concesión ni sustituye a las concesiones nacionales.

\begin{tabular}{|c|c|}
\hline $\begin{array}{l}\text { PATENT } \\
\text { COOPERATION } \\
\text { TREATY } \\
\text { WORLD } \\
\text { INTELLECTUAL } \\
\text { PROPERTY } \\
\text { ORGANIZATION }\end{array}$ & $\begin{array}{l}\text { El Tratado de Cooperación en materia de Paten- } \\
\text { tes (PCT) es un Tratado multilateral, administrado } \\
\text { por la OMPI (Organización Mundial de la Propiedad } \\
\text { Intelectual) o WIPO (World Intellectual Property Or- } \\
\text { ganization), que se creó en 1970, y desde } 1974 \text { es } \\
\text { una agencia de Naciones Unidas. Tiene su sede en } \\
\text { Ginebra y supervisa los Acuerdos multilaterales so- } \\
\text { bre los aspectos jurídicos y administrativos de la } \\
\text { propiedad intelectual. }\end{array}$ \\
\hline
\end{tabular}


Los documentos de patente publicados por OMPI en virtud del tratado PCT se reconocen por las letras WO.

Además, la OMPI coordina a las Oficinas de Patentes y Marcas de 184 países que son Estados Miembros. Gracias a esta coordinación existe una gran armonización en las “Leyes de Patentes y Marcas" de los distintos países, así como en las publicaciones de las patentes que están normalizadas y clasificadas, según la "Clasificación Internacional de Patentes", lo que permite recuperar tecnologías similares de un mismo campo de la técnica.

\section{DOCUMENTOS DE PATENTE}

Las solicitudes de patente, en la mayoría de los países, se publican a los 18 meses de su presentación con el objeto de divulgar la información tecnológica contenida en ellas. A estas publicaciones se les conoce como "Documentos de Patente" y se les asigna un número alfanumérico único que empieza con las dos letras del país donde se ha solicitado la protección, seguida del número secuencial designado por esa oficina (ES 2113342).

Posteriormente, tras un informe de novedad y de actividad inventiva, y un período de oposiciones, si se llegan conceder, se publican las patentes concedidas. Si se deniegan, no aparece esta segunda publicación.

La ventaja de los documentos de patente es que describen la tecnología objeto de la invención, de forma estructurada, en una descripción que incluye antecedentes del estado de la técnica, problemas que intenta solucionar la invención, ventajas que aporta, la aplicación industrial de la invención, etc. Además contienen un resumen que se incorpora a las bases de datos y, sobre todo, las reivindicaciones que son las que definen legalmente el alcance de la protección de la patente.

El folleto que publican las oficinas con cada solicitud de patente contiene una PRIMERA PÁGINA en la que figuran los datos bibliográficos con referencias normalizadas a escala mundial de fecha de presentación (22), prioridad (30), publicación (43), así como los datos del solicitante (71) y del inventor (72), la clasificación internacional (51), el título de la solicitud (54) y el resumen (57), haciendo fácilmente localizable al titular para cualquier tercero interesado en esa tecnología.

Después de esta primera página, va la descripción que debe ser clara y completa, las reivindicaciones ("claims", en inglés) que deben tener base en la descripción y, si es necesario, para entender la invención, unos dibujos. 
(19)

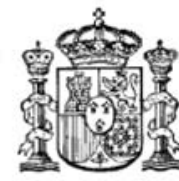

OFICINA ESPAÑOLA DE PATENTES Y MARCAS

ESPAÑA

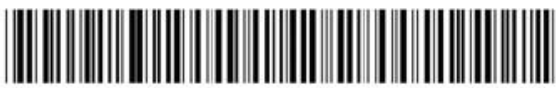

(11) Número de publicación: $2113 \mathbf{3 2 4}$

(21) Número de solicitud: 9602149

(51) Int. Cl. ${ }^{6}$ : A61K 35/78
(22) Fecha de presentación: $\mathbf{1 1 . 1 0 . 9 6}$

(43) Fecha de publicación de la solicitud: $\mathbf{1 6 . 0 4 . 9 8}$

(43) Fecha de publicación del folleto de la solicitud: 16.04 .98
(71) Solicitante/s: Josefa Gil García

Avenida del Albir, 35
03001 Alicante, Es

03001 Alicante, ES
Juan Mendoza Acevedo

(72) Inventor/es: Mendoza Acevedo, Juan y

Gil García, Josefa

(74) Agente: Pons Ariño, Angel

(54) Título: Composición de un producto para tratamiento de úlceras del aparato digestivo.

(57) Resumen:

Composición de un producto para el tratamiento de úlceras del aparato digestivo en la que se utilizan 125

gramos de la planta Cistus Ladanifer, conocida como

Jara, en un litro de agua. La Jara se utiliza en estado

seco con las hojas, tallos y flores de dicha planta.

\section{PROTECCIÓN DE INVENCIONES EN OTROS PAÍSES}

El solicitante tiene un periodo de 12 meses desde la fecha de presentación de su solicitud para presentarla en otros países miembros del "Convenio de la Unión de París" y de la "Organización Mundial del Comercio" (OMC), manteniendo como fecha de presentación la de la solicitud inicial.

Este "derecho de prioridad" puede generar una "familia de patentes" (varias solicitudes que se basan en la misma prioridad, o dicho de otro modo, que protegen la misma invención).

En este caso, cada oficina hace su publicación. Por ello, si encontramos un documento en un idioma que no conocemos podemos localizar otro de la misma familia en un idioma conocido. 


\section{EL DOBLE PAPEL DE LAS PATENTES}

Las patentes no solo sirven para proteger las innovaciones técnicas de los inventores sino también, y más importante, son de utilidad por la información técnica y tecnológica que incluyen. Hay que distinguir entre protección jurídica e información tecnológica contenida en los documentos. El uso de esta información no está expuesto a acciones legales en contra por parte del titular de la patente ya que es la base para el avance tecnológico.

Los documentos de patente como fuente de información proporcionan:

- Información técnica: describen la tecnología de forma clara y completa.

- Información comercial: contiene datos sobre el titular, el inventor, etc.

- Información legal: cuál es el objeto protegido, desde cuando está en vigor, etcétera.

Los documentos de patente contienen más del 80\% de toda la información tecnológica mundial, por eso, se les considera una de las fuentes de información más completa, accesible, práctica y actualizada sobre los desarrollos innovadores de todas las áreas tecnológicas. Además, mucha de esta información no se publica ni en libros ni en revistas, la única forma de acceder a ella es consultando estos documentos.

En resumen, una patente se puede solicitar en un país consiguiendo una protección jurídica tan sólo en el país donde se solicita; ahora bien, la información tecnológica contenida en la patente, y que se publica como folleto, se distribuye a escala mundial, recogiéndose en bases de datos y en Internet.

En la base de datos de todo el mundo existe una colección de patentes publicadas desde 1836 de 71 países.

En número de documentos de patentes que se pueden consultar asciende a más de 45 millones.

Actualmente, hay más de sesenta millones de documentos de patentes, cada uno con su número alfanumérico único, y están accesibles por Internet a través de Esp@cenet3.

3 Esp@cenet es una base de datos creada por la Oficina Europea de Patentes en colaboración con las oficinas nacionales de patentes de países europeos, y está accesible por www.epo.org, en inglés y www.oepm.es, en español. 
Es por este contenido técnico y tecnológico que las patentes juegan un papel muy importante en transferencia de tecnología. Fue la UNCTAD (Conferencia de Naciones Unidas para Comercio y Desarrollo) quien publicó en 1975 un libro sobre: "la función del sistema de patentes en la trasmisión de tecnología a los países en desarrollo”.

La Oficina Española de Patentes y Marcas presentó un documento en la VII Conferencia de las Partes del $C D B$ celebrado en 2004 en Kuala Lumpur sobre el papel de las patentes en la transferencia de tecnologías según el artículo 16 del $C D B$ con ejemplos relacionados con la conservación y usos de la biodiversidad.

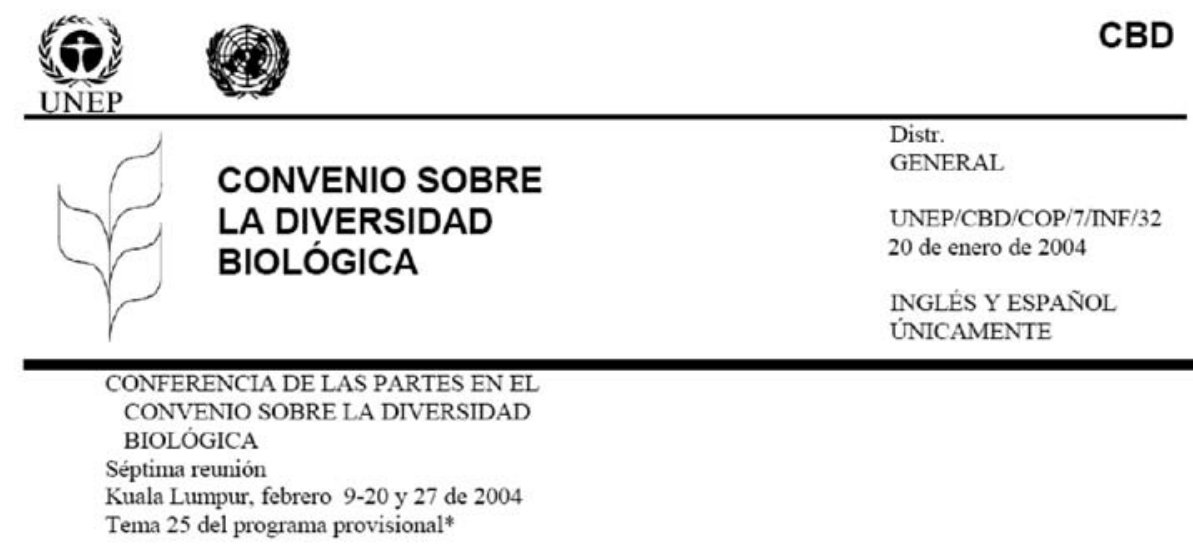

\section{TRANSFERENCIA DE TECNOLOGÍA Y COOPERACIÓN TECNOLÓGICA (ARTÍCULOS 16 Y 18)}

Las patentes como fuente de información tecnológica en el proceso de transferencia de tecnologia

\section{Comnnicado del Gobierno de España}

1. A solicitud del Gobierno de Espana, por medio del presente, el Secretario Ejecutivo hace circular, para información de los participantes de la séptima reunión de la Conferencia de las Partes en el Convenio sobre la Diversidad Biológica, un documento sobre las patentes como fuente de información tecnológica en el proceso de transferencia de tecnología preparado por la Oficina Española de Patentes y Marcas.

2. El documento se hace circular en la forma y en los idiomas en los que fue recibido por la Secretaría del Convenio sobre la Diversidad Biológica.

Una vez comprendido cuáles son los objetivos de los Derechos de Patente y el papel de las patentes en la transferencia de tecnología a los países en desarrollo, se puede comprender la mención a las patentes que el CDB hace en su Artículo 16 que se refiere al "Acceso y Transferencia de Tecnologías" y examinar la relación de las patentes con la biodiversidad.

\section{Patentes y biodiversidad}

Las patentes que protegen invenciones que se basan en la biodiversidad se pueden dividir en dos grandes grupos: 
- Patentes de biodiversidad

SIN técnicas de ingeniería genética

\section{- Patentes de biotecnología}

CON técnicas de ingeniería genética

- Las patentes de biotecnología protegen en sus reivindicaciones el material genético manipulado por técnicas de ingeniería genética o simplemente aislado de su medio natural y expresado en otras especies, sea este material moléculas de ADN, ARN, polipéptidos recombinantes, vectores, plásmidos, etcétera.

\section{ES $2259251 \mathrm{~A} 1$}

\section{REIVINDICACIONES}

1. Moléculas de DNA recombinante caracterizadas por SEQ ID NO: 1 que codifican péptidos con actividad ribonucleolítica y que poseen al menos un epítopo alergénico común con el alergeno principal de Aspergillus spp. denominado Aspf1.

2. Moléculas de DNA recombinante caracterizadas por SEQ ID NO: 1 que codifican péptidos con propiedades citotóxicas y/o alergénicas atenuadas.

3. Moléculas de DNA recombinante caracterizadas por SEQ ID NO: 1 que codifican péptidos con capacidad alterada, con respecto a la $\alpha$-sarcina y Aspf1, para interaccionar con membranas lipídicas.

4. Moléculas de DNA recombinante, según reivindicaciones anteriores, o modificaciones de dichas moléculas, que codifican polipéptidos unidos a un polipéptido adicional, o modificados química o enzimáticamente.

5. Polipéptidos recombinantes de $\Delta(6-21)$ Aspf1, o fragmentos de dichos polipéptidos, según reivindicaciones anteriores, caracterizados por la secuencia dada en SEQ ID NO: 1 y 2, que presentan la antigenicidad de, al menos, un epítopo de Aspf1.

20

6. Polipéptidos recombinantes de $\Delta(6-21)$ Aspf1, o fragmentos de dichos polipéptidos, según reivindicaciones 1,2 , 3 y 4, caracterizados por la secuencia dada en SEQ ID NO: 1 y 2 , que presentan actividad ribonucleolítica alterada con respecto a la $\alpha$-sarcina, las Aspf1 y la RNasa U2.

25 7. Polipéptidos recombinantes de $\Delta(6-21)$ Aspf 1, o fragmentos de dichos polipéptidos, según reivindicaciones 1,2 3 y 4, caracterizados por la secuencia dada en SEQ ID NO: 1 y 2, que presentan actividad citotóxica alterada con respecto a la $\alpha$-sarcina, las Aspf1 y la RNasa U2.

8. Polipéptidos recombinantes de $\Delta(6-21)$ Aspf 1 , o fragmentos de dichos polipéptidos, según reivindicaciones 1 , 2, 3 y 4, caracterizados por la secuencia dada en SEQ ID NO: 1 y 2, que presentan una capacidad alterada para interaccionar con membranas con respecto a la $\alpha$-sarcina, la Aspf1 y la RNasa U2.

9. Un vector de expresión procariota, y preferentemente pINPG o pET, que contenga cualquiera de las secuencias de nucleótidos descritas en las reivindicaciones 1 a 4, y que permita la producción recombinante de cualquiera de los polipéptidos según reivindicaciones 5 a 8 .

10. Un vector de expresión eucariota, y preferentemente $\mathrm{pHILD} 2, \mathrm{pHILS} 1, \mathrm{pPIC} 9$ o pPICZ $\alpha$, que contenga cualquiera de las secuencias de nucleótidos descritas en las reivindicaciones 1 a 4, y que permita la producción recombinante de cualquiera de los polipéptidos según reivindicaciones 5 a 8 .

\section{A) Especies y Estrategias de Protección en Biotecnología}

Las empresas que trabajan en biotecnología suelen utilizar especies conocidas de plantas, microorganismos o de animales:

- La primera planta cuyo genoma se secuenció por entero fue la Arabidopsis thaliana. En general, si se trabajan con plantas es habitual hacerlo con tomate, trigo, soja, maíz, leguminosas, tabaco, etc. 
- Si se utilizan microorganismos suelen ser: Escherichia coli, Salmonella, Agrobacterium tumefaciens, Saccharomyces cerevisae, Candida albicans, etc.

- Si se trabajan con animales, lo más habitual es utilizar ratones, ratas, hamsters, cobayas y, aunque menos, ovejas, cabras, vacas, cerdos, etc.

- Si se trabaja en mejora de antibióticos, se usan Streptomyces, Penicillium, Aspergillus, etc.

(54) Título: Procedimiento para la producción y purificación de somatostatina en células de Escherichia coli a partir de la expresión en las mismas del gen codificante clonado en el vector pGRV1.
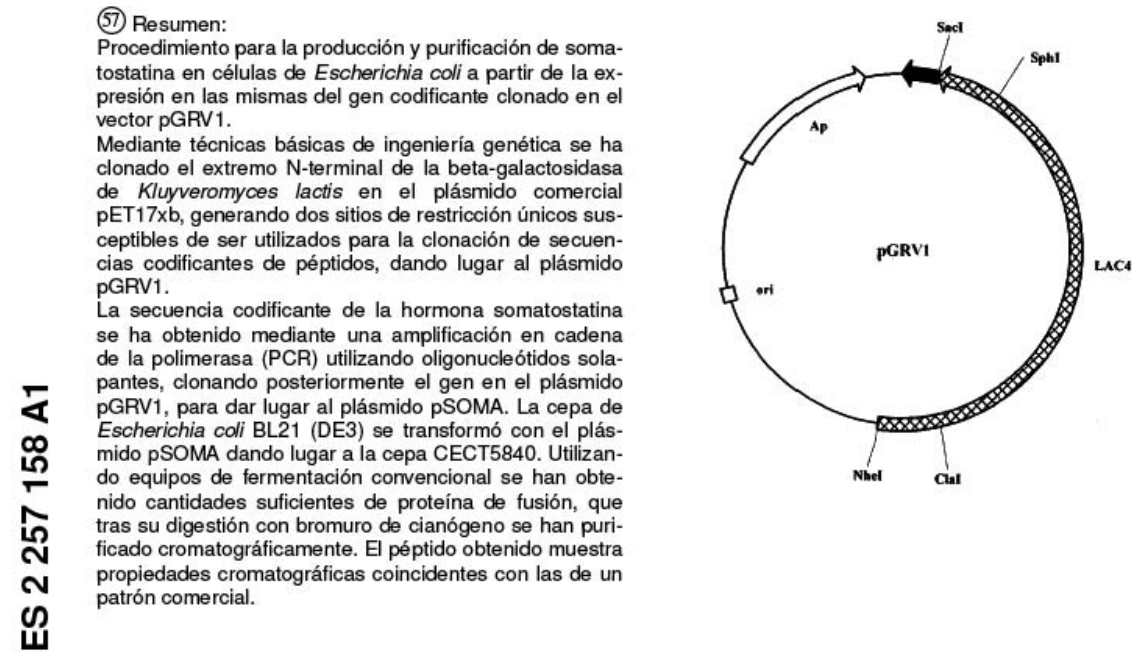

Según las solicitudes de patente de biotecnología, se introducen mejoras en especies ya conocidas por técnicas ingeniería genética. Muchos microorganismos son empleados como vehículos o vectores para introducir las secuencias de ADN. En estas solicitudes hay, por lo tanto, divulgación del material genético y de las modificaciones que se hace con él.

\section{B) Patentes de Biodiversidad}

- Sin manipulación genética del recurso, protege el uso del recurso o procedimientos de extracción, estabilización del extracto, composición sinérgica de varios componentes de origen biológico, etc.

Uso del recurso. Un ejemplo de patente con reivindicaciones de uso lo tenemos en la solicitud PCT, WO 0006182 que reivindica el uso de un extracto para la fabricación de un medicamento para el tratamiento del sida. 


\section{CLAIMS}

1. The use of an extract from an Aristolochia species or one or more compounds isolable therefrom, for the manufacture of a medicament for the treatment of AIDS.

2. The use of an extract from an Aristolochia species or one or more compounds isolable therefrom for the manufacture of a medicament for preventing or reversing cachexia in AIDS patients.

Esta forma de redactar en función del uso de un extracto para la fabricación de un medicamento es habitual en los países europeos y otros países donde existe la prohibición de patentar métodos terapéuticos.

La existencia de esta prohibición es en interés de la salud pública para asegurar que las patentes no interfieran con métodos no industriales relacionados con la actividad de los médicos y otros profesionales sanitarios.

Otro ejemplo sería el presentado como solicitud internacional PCT por una solicitante e inventora de Méjico, y publicado por OMPI como: WO 2006004386 cuyo objeto de protección es el "Uso del extracto de Ginkgo biloba para la preparación de una medicina para tratar la enfermedad del Parkinson”.

(12) SOLICITUD INTERNACIONAL PUBLICADA EN VIRTUD DEL TRATADO DE COOPERACIÓN EN MATERIA DE PATENTES (PCT)

\section{(19) Organización Mundial de la Propiedad Intelectual Oficina internacional}

(43) Fecha de publicación internacional 12 de Enero de 2006 (12.01.2006)

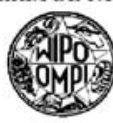

PCT
(10) Número de Publicación Internacional WO 2006/004386 A1

(51) Clasilicación Internacional de Patentes ${ }^{7}$ : A61K 35/78, (74) Mandatario: ROJAS CASTANEDA, Adolfo; Calle 10 A61P 25/16 $\mathrm{N}^{\circ} 4406$, Col. Aguilera, C.P. 02900 México, D.F. (MX).

(21) Número de la solicitud internacional: PCT/MX2004/000042

(22) Fecha de presentación internacional: 2 de Julio de 2004 (02.07.2004)

(25) Idioma de presentación: español (26) Idioma de publicación: español

(71) Solicitante e

(72) Inventor: ROJAS CASTAÑEDA, Patricia [MX/MX]; Calle 10, $\mathrm{N}^{\circ} 4406$, Col Aguilera, C.P. 02900 México, D.F (MX).

(81) Estados designados (a menos que se indique otra cosa. para toda clase de protección nacional admisible): $\mathrm{AE}$ AG, AL, AM, AT, AU, AZ, BA, BB, BG, BR, BW, BY $\mathrm{BZ}, \mathrm{CA}, \mathrm{CH}, \mathrm{CN}, \mathrm{CO}, \mathrm{CR}, \mathrm{CU}, \mathrm{CZ}, \mathrm{DE}, \mathrm{DK}, \mathrm{DM}, \mathrm{DZ}$ EC, EE, EG, ES, FI, GB, GD, GE, GH, GM, HR, HU, ID, II, IN, IS, JP, KE, KG, KP, KR, KZ, LC, LK, LR, LS, LT, LU, LV, MA, MD, MG, MK, MN, MW, MX, MZ, NA, NI, NO, NZ, OM, PG, PH, PI., PT, RO, RU, SC, SD, SE, SG, SK, SL, SY, TJ, TM, TN, TR, TT, TZ, UA, UG, US, UZ VC, VN, YU, ZA, ZM, ZW

(84) Estados designados (a menos que se indique otra cosa para toda clase de protección regional admisible): ARIPO

(Continua en la página siguiente)

(54) Tille: USE OF GINKGO BILOBA EXTRACT FOR THE PREPARATION OF A MEDICINE THAT IS USED TO TREAT PARKINSONS DISEASE

(54) Título: USO DE UN EXTRACTO DEL GINKGO BILOBA PARA PREPARAR UNA MEDICINA PARA TRATAR LA EN FERMEDAD DE PARKINSON 
En cambio, en otros países como es el caso de Estados Unidos se permite patentar métodos terapéuticos. A título de ejemplo se puede citar, la patente americana US 4598069 cuyas reivindicaciones se refieren a un método para tratar diabetes.

What is claimed is:

1. A method of treating diabetes which comprises administering to a patient afflicted with diabetes a therapeutically effective amount of a hypoglycemic composition which contains as an effective component a polysaccharide contained in aloes of the family Liliaceae and having hypoglycemic activity and water solubility.

2. The method of claim 1 wherein the aloe of the family Liliaceae is selected from the group of arborescent aloe (Aloe arborescens Mill.); cape aloes (Aloe ferox Mill., Aloe vera L., Aloe africana Mill.); nathal aloes

45 (Aloe barberae Dyer, Aloe soccotrina Lam.); zanzibar aloe (Aloe perryi Baker); curacau aloe (Aloe barbadensis Miller); and jaffarabad aloes (Aloe vera $L$. chinensis Haw. Aloe striatula Haw.).

Otro ejemplo de patentes de biodiversidad pero referido a una composición sinérgica de varios extractos de plantas para el tratamiento de enfermedades articulares es la solicitud PCT publicada como WO 2005092355:

(54) Title: PHYTO-COMPOSITION FOR THE TREATMENT OF ARTICULAR DISEASES

(54) Título: FITOCOMPOSICION PARA EL TRATAMIENTO DE ENFERMEDADES ARTICULARES

(57) Abstract: The invention relates to a phyto-composition for the treatment of articular diseases, comprising: a) between 0.01 in and 26 wt.- \% of an extract of Curcuma longa (turmeric); b) between 30 and $80 \mathrm{wt}$. \% of an extract of Harpagophytum procumbens In (devil's claw); c) between 0.01 and 25 wt.- \% of an extract of Filipendula ulmaria (meadowsweet); and d) between 7 and 35 wt.- \% 7 of Oenothera biennis oil (common evening primrose). The inventive phyto-composition can be used together with a pharmaceutically-acceptable excipient in order to produce a pharmaceutical composition that can be used for the treatment of articular diseases, particularly rheumatoid arthritis and osteoarthritis.

(57) Resumen: Se describe una fito-composición para el tratamiento de enfermedades articulares, que comprende: a) de $0.01 \%$ a $26 \%$ en peso de un extracto de Curcuma longa (cúrcuma); b) de $30 \%$ a $80 \%$ en peso de un extracto de Harpagophytum procumbens (garra del diablo); c) de $0.01 \%$ a $25 \%$ en peso de un extracto de Filipendula ulmaria (ulmaria); y d) de $7 \%$ a $35 \%$ en peso de aceite de Oenothera biennis (onagra). Dicha fito-composición siendo utilizada en combinación con un vehículo farmacéuticamente aceptable para obtener una composición farmacéutica útil en el tratamiento de enfermedades articulares, particularmente, artritis reumatoide y osteoartritis. 


\section{C) Especies y Estrategias de protección en Biodiversidad}

En las patentes que utilizan la biodiversidad sin emplear técnicas de ingeniería genética, las estrategias de protección son diferentes. En efecto:

EXTRACTOS VEGETALES
Los extractos vegetales permiten presentar bajo una forma fácilmente utilizable en cosmética, los
activos de las plantas; flores, cortezas, raices,...
Los solventes que permiten extraer los activos son el agua, el propileno-glicol, el butileno-glicol,
glicerina, alcohol, ....
Los más corrientes son los extractos hidroglicólicos cuyos solventes son el agua y un glicol ( ya
sea el propileno-glicol o el butileno-glicol). La proporción respectiva del agua y del glicol es $50: 50$.
El vegetal es puesto a macerar en la solución elegida. Si la planta está seca, la concentración
será de 10\% (en peso). Para las plantas o frutos frescos, la concentración será mucho más
importante. Después de moler las plantas en el solvente, agitar y macerar, el liquido estará filtrado.
Para un mayor respeto de la planta y preservación de todos los activos ; hemos escogido trabajar
a una temperatura y privilegiar las maceraciones largas (minimo doce dias para un extracto
hidroglicólico).
A continuación, los extractos son sistemáticamente analizados y medida su limpieza
bacteriológica.
Los extractos lipidicos son extractos vegetales cuyo único solvente es un aceite o una mezcla de
aceites (ver la definición de extractos lipidicos).

- Hay empresas que solicitan patentes para proteger el extracto biológico cuando la especie es nueva y no ha sido descrito su uso.

Para conseguir un extracto es importante tener en cuenta el solvente empleado para hacer la extracción.

El solvente puede ser acuoso, glicólico, acetónico, lipídico, etc. Así en la industria cosmética son importantes los solventes hidroglicólicos ${ }^{4}$.

\section{Aislamiento de ADN}

Esta forma de extracción difiere de los protocolos que se emplean para extraer y purificar el ADN de plantas, que incluye cuatro pasos indispensables:

1. Ruptura de tejidos y paredes celulares.

2. Ruptura de membranas.

3. Inhibición de enzimas que destruyen el ADN

4. Extracción de contaminantes.

4 http://www.ieslabo.com/espagnol/extrait_veg_esp.htm 
Estos pasos se basan en la estructura fisicoquímica del ADN, que aparte de ser una molécula de alto peso molecular, larga y delicada, es un ácido capaz de formar sales con iones cargados positivamente. Además, es soluble en soluciones concentradas de sales (p.e. sal de cocina), pero insoluble en alcoholes tipo (etanol o isopropanol). Adicionalmente, el ADN es destruido (depurinado) a $\mathrm{pH}$ ácido $(<4,0)$, es insoluble a pH 5,6 y soluble a pH 8,0 (Howell, 1973) $)^{5}$.

Según los solventes elegidos y el protocolo seguido se extraen unas sustancias u otras. En un extracto vegetal, lo habitual es que haya principios activos de utilidad médica o cosmética, en cambio, hay poca presencia de material genético.

- Otro tipo de patentes son las de "uso de un extracto" que es habitual cuando la especie ya es conocida pero no su uso médico/cosmético (ya se han visto ejemplos).

En estos dos tipos de solicitudes puede haber conocimiento tradicional asociado que no es habitual en las patentes de biotecnología. De hecho, las patentes que han resultado más conflictivas como la de la cúrcuma, el neem, la ayahuasca, el kava-kava eran de este tipo y no divulgan material genético.

- Hay empresas que no patentan ni el extracto ni sus usos, sino los metabolitos secundarios o moléculas aisladas del extracto y que constituyen principios activos para nuevos medicamentos o nuevos cosméticos.

Está por ver en qué categoría entrarían estos metabolitos secundarios o moléculas en los debates sobre " $A B S$ " y si se considerarán como productos o derivados. Según se incluyan o no, estas patentes podrían estar fuera del reparto de beneficios a pesar de aislarse directamente del extracto biológico.

Una vez localizados estos metabolitos, la vía a seguir puede variar según la complejidad de la molécula. Si es sencilla, se podrán sintetizar en laboratorio, e incluso, localizar el gen(es) que la codifica(n). Pero, si la molécula es compleja, ninguna de estas dos vías es posible: de hecho, cuanto más compleja sea la molécula menos se recurre a la síntesis o a los genes. En estos casos, la vía de obtención es o el aislamiento y purificación de principios activos contenidos en el extracto, o la semisíntesis de la molécula compleja a partir de precursores.

En general, se puede decir que las empresas que trabajan en especies silvestres, tienen más interés en explorar especies nuevas, cuyo uso no es conocido o no está divulgado en occidente. Es un sector donde es importante la bioprospección.

5 Pedro J. Rocha Salavarrieta: “Teoría y Práctica para la extracción y purificación del ADN de palma de aceite". Palmas, 2002. Vol. 23, n. ${ }^{\circ}$, pp. 9-17. 


\section{BIOPROSPECCIÓN}

Se conoce como Bioprospección al proceso de búsqueda y evaluación que permite identificar, seleccionar y aislar componentes útiles de especies ya sean plantas, animales o microorganismos.

Según publicaciones de la UICN, las industrias implicadas en la bioprospección son muy diferentes en tamaño y usan la biodiversidad en forma muy diferente ${ }^{6}$.

De acuerdo con esta publicación, los sectores que más contratos de bioprospección hacen son el farmacéutico, el cosmético y el de fitomedicinas, es decir, sectores que trabajan recolectando muestras de especies silvestres.

Hoy en día se sabe que puede llegar a recolectar diez mil a cien mil muestras biológicas al adentrarse en una selva o un bosque, sean árboles, matorrales, lianas, insectos, hongos, líquenes, semillas, bulbos, resinas, y/o aceites.

Hay empresas muy especializadas que recogen sólo un tipo de muestras como son insectos, o lianas porque trabajan únicamente con un tipo de material biológico.
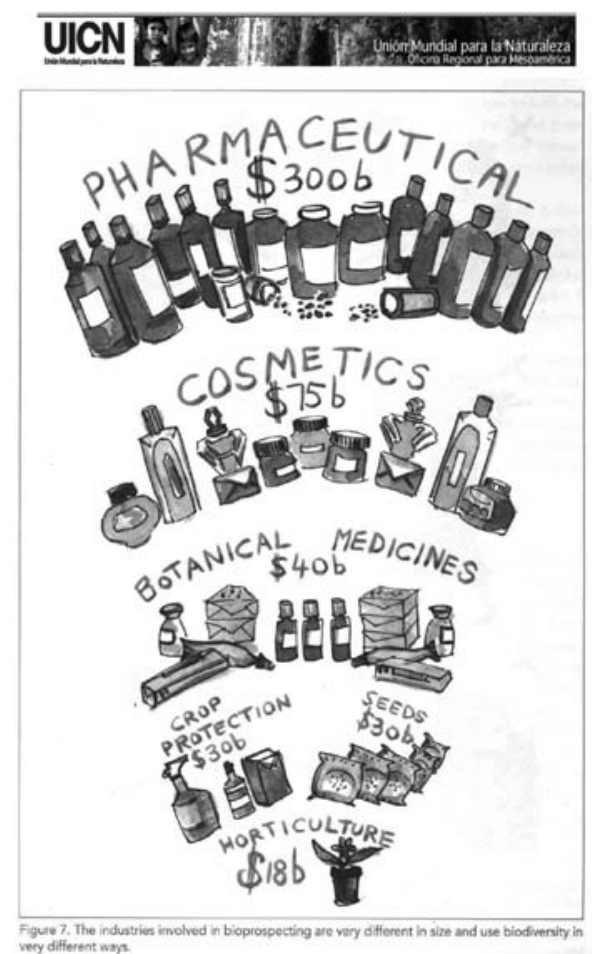

Además, lo habitual es que los principios activos estén localizados sólo en una parte del organismo, como son las hojas (Ginkgo biloba), la corteza (taxol, Prunus africana) las raíces (ginseng) o los bulbos, etc. Cuando se conoce la parte del organismo que interesa, sólo se recolecta esa parte en concreto. De esas partes, se preparan los extractos biológicos o se aíslan los metabolitos secundarios que resultan ser principios activos.

Como se ha dicho antes, según se hagan extracciones acuosas, etanólicas, lipídicas, acetónicas, etc. resultan extractos diferentes con distintos principios activos no basados en material genético sino en moléculas con actividad antioxidantes o antitu-

6 Sarah A. Laird \& Rachel Wynmberg: “Biodiversity prospecting \& Access and Benefit-Sharing”, 2004, p. 10. 
morales o antidiabéticos o antiinflamatorios, etc. Los extractos o los principios activos se incorporan a medicamentos o cosméticos que se comercializan.

Para llegar a ello, las muestras biológicas que se recogen son sometidas a una búsqueda sistemática de compuestos ("screening") con el objeto de encontrar alguna aplicación de estos compuestos, que pueda tener un valor potencial o real, convirtiendo estas muestras de partes de organismos en "recursos biológicos" según la definición del Convenio sobre Diversidad Biológica (CDB, Art. 2).

Convenio sobre Diversidad Biológica (CDB), en su Artículo 2, Términos utilizados:

- “Por 'recursos biológicos' se entienden, los recursos genéticos, los organismos o partes de ellos, las poblaciones o cualquier otro tipo del componente biótico de los ecosistemas de valor o utilidad real o potencial para la humanidad".

- "Por 'recursos genéticos' se entienden el material genético de valor real o potencial".

- “Por 'material genético' se entiende todo material de origen vegetal, animal, microbiano o de otro tipo que contenga unidades funcionales de la herencia".

De estas muestras se pueden aislar genes pero esto no se hace siempre y sería, en cualquier caso, más adelante en un nivel posterior del proceso de investigación, que podría tardar años.

\section{INVESTIGACIÓN DEL CÁNCER}

La investigación del Cáncer es uno de los sectores que más utilizan las especies silvestres ya sea de selvas o de los fondos de los mares. Los productos antitumorales que se encuentran en los extractos son moléculas muy complejas.

Dos ejemplos ilustrativos: el caso del "Taxol" que se encuentra en la corteza de los tejos o el caso de "Yondelis", en la ascidia Ecteinascidia turbinata ${ }^{8}$. En ambos casos, la molécula es tan com-

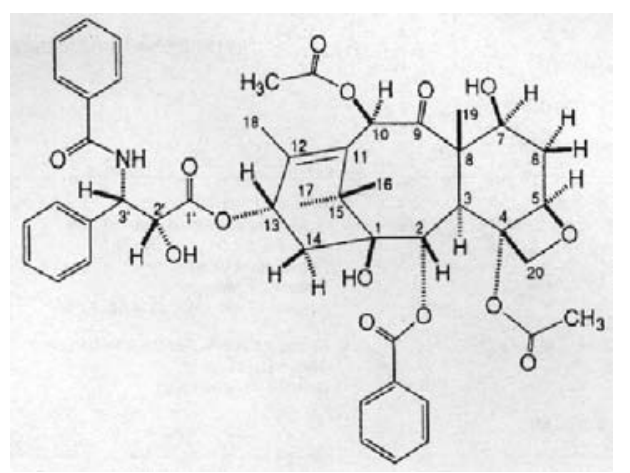

7 Casos estudios en la Revista Marchamos n. $15 \mathrm{y} \mathrm{n} .^{\circ} 30$, respectivamente, publicada por la Oficina Española de Patentes y Marcas. Localizables en http://www.oepm.es. 
pleja que para su comercialización se realiza una semisíntesis a partir de un precursor, pero no se sintetiza "de novo" ni se buscan los genes que la producen, proceso que resulta caro y laborioso.

No se puede decir que se va a la selva a por genes. Lo correcto es decir que se va a por muestras biológicas y el primer recurso al que se llega en una investigación tras un proceso de bioprospección es al recurso biológico que para muchos usuarios es el más inmediato para dar beneficios.

\section{REPARTO DE BENEFICIOS}

Objetivos del Convenio sobre Diversidad Biológica ( $C D B)$

1. Conservación de diversidad biológica

2. Utilización sostenible de sus componentes

3. Participación justa y equitativa en los beneficios que se deriven de la utilización de los recursos genéticos.

Durante las negociaciones del $C D B$, muchos países lucharon para incluir, como uno de los objetivos de este Convenio, la distribución de los beneficios derivados de la utilización de los recursos genéticos.

La cuestión del reparto de beneficios está muy ligada al acceso a recursos genéticos. El Convenio sobre Diversidad Biológica regula en su Artículo 15, el "Acceso a los Recursos Genéticos".

El Artículo 15 del CBD

- En reconocimiento de los derechos soberanos de los Estados sobre sus recursos naturales, la facultad de regular el acceso a los recursos genéticos incumbe a los gobiernos y está sometida a la legislación nacional (Art. 15-1).

- Cada Parte procurará facilitar a otras Parte el acceso a los RG.... y no imponer restricciones... (Art. 15-2).

- Cuando se conceda el acceso se hará en "Términos Mutuamente Acordados" (MAT) (Art. 15-3) y sometido al "Consentimiento Fundamentado Previo" (PIC) de la Parte que proporciona el recurso (Art. 15-4).

En efecto, según el Art. 15 del $C D B$, los gobiernos de las Partes Contratantes del $C D B$ pueden legislar el acceso y cuando se conceda se hará cumpliendo un PIC (siglas

256 en inglés, "Prior Informed Consent") y un MAT("Mutually Agreed Terms"). 


\section{DEFINICIONES CONFUSAS PARA LOS USUARIOS}

El hecho de que la definición de "recurso biológico" sea más amplia que "recurso genético" (Art. 2 del CDB), y de que el acceso regulado por el CDB se refiere sólo a los "recursos genéticos" (Art. 15 del CDB) se presta a confusión para los usuarios que hacen bioprospección para recoger muestras biológicas de especies silvestres y que no utilizan el material de herencia.

Estos usuarios de especies silvestres se preguntan si están en la obligación de cumplir con las leyes de acceso y reparto de beneficios ( $A B S$, "Access and Benefit Sharing" por sus siglas en inglés).

Tal vez se quiso evitar que la madera, que es un recurso biológico, se incluyera en los objetivos del $C D B$. Sin embargo, muchos árboles tienen en su corteza principios activos como los tejos o el Prunus africana; principios que se incorporan como activos a medicamentos que han conseguido gran cantidad de beneficios.

Es más, los sectores más involucrados en bioprospección utilizan partes de organismos, es decir, trabajan en primera instancia según la propia definición del $C D B$ con un recurso biológico y, de forma inmediata, tienen posibilidad de conseguir beneficios de ese recurso. En cambio, para estos usuarios trabajar con el material genético (recurso genético) no es inmediato, pueden tardar años, o incluso no utilizarlo nunca.

En efecto, para los sectores de fitomedicinas y cosmética, los extractos biológicos, los productos y derivados de los extractos, son el punto de partida para conseguir beneficios. Esta vía es más fácil y sencilla que hacer un detenido estudio genético para conocer qué genes están implicados en la producción de una molécula compleja que se encuentra en el extracto.

Ya se ha mencionado antes que las solicitudes de patentes de este sector no divulgan ninguna secuencia de material genético, en cambio si protegen el extracto biológico o el uso de extracto con fines médicos, cosméticos, etc.

De hecho, las Oficinas de Patentes, a nivel mundial, clasifican de forma muy distinta las patentes biológicas que llevan divulgaciones de material genético como son secuencias de genes, nucleótidos, aminoácidos, vectores, plásmidos ( $\mathrm{C}_{12} \mathrm{~N}, \mathrm{C} 12 \mathrm{Q}$, Co7K... ) y las distinguen de aquellas solicitudes que se refieran a usos de extractos $\mathrm{O}$ de procedimiento de extracción o de estabilización o a composiciones de varios extractos pero que no tocan el material genético del extracto biológico (A61K ....). En efecto, las Oficinas de Patentes son conscientes de las diferencias entre ambos tipos de invenciones. 
Según datos de la base de datos mundial de patentes Derwent World Patent Index $(D W P I){ }^{8}$ hay cerca de doscientos mil documentos clasificados en la subclase $\mathrm{C}_{12} \mathrm{~N}$, que recogen las técnicas de ingeniería genética. Los procesos microbiológicos o enzimáticos de la subclase $\mathrm{C} 12 \mathrm{Q}$ se acercan a cien mil documentos. En la subclase C07K donde se clasifican los péptidos procedentes de seres vivos así como hormonas, inmunoglobulinas, etc. pasan de los cien mil documentos. Las plantas transgénicas de la subclase $\mathrm{A} 01 \mathrm{H}$ superan las veinte mil y los animales transgénicos del grupo A01K67/0o los diez mil. Como muchos documentos pueden tener dos o más clasificaciones de estas subclases, se ha comprobado, al hacer la intersección, que más de trescientos cincuenta mil documentos distintos están clasificados en estas subclases.

Por otra parte, en cuanto a extractos biológicos, son minoritarios los extractos de algas, hongos, líquenes, y los más patentados son los extractos de plantas. Según la base de datos DWPI, más de sesenta mil documentos llevan clasificación de extracto de plantas $\left(A 61 K_{3} 5 / 78, A 61 K_{3} 6 \ldots\right.$... ). El número real puede ser superior puesto que existen solicitudes muy antiguas anteriores al año 1968 que se refieren a plantas medicinales y no están recogidas por esta base de datos. En cualquier caso, no quiere decir esta cifra dada por DWPI que figuren sesenta mil especies de plantas distintas en los documentos de patentes puesto que hay especies muy patentadas y, en cambio, otras especies conocidas no figuran nunca en documentos de patentes.

Así, como ejemplos de especies muy citadas en las patentes, están las múltiples patentes que se refieren a la especie Aloe vera, utilizada en alimentos, en cosméticos ${ }^{9}$ y por su uso terapéutico para diabetes, para esclerosis múltiple, como antiinflamatorio, etc.

Otra especie, superviviente del Jurásico, como el Ginkgo biloba figura en varios cientos de documentos de patente de distintos países porque de sus hojas se extraen principios activos que mejoran de la microcirculación del cerebro. Según los distintos documentos se preparan extractos acuosos, etanólicos, lipídicos, etc. Entre los múltiples usos destaca el uso del Ginkgo biloba para mejorar la memoria, la función cognitiva y mental así como componente de nutraceúticos para prevenir la enfermedad del Parkinson, de la demencia senil y del Alzheimer.

También resulta relevante la familia de las Labiadas, especies como el romero, la lavanda, el tomillo, la salvia, son utilizadas, solas o con otros componentes, en mu-

8 Derwent World Patent Index (DWPI) es una base de datos de patentes publicada por Thomson Reuters que contiene 15 millones de referencias que cubren más de 35 millones de documentos de patentes emitidos por 41 autoridades mundiales que incluye Europa, Japón, Estados Unidos y la mayoría de las oficinas de Asia-Pacífico.

http://thomsonreuters.com/products_services/legal/legal_products/intellectual_property/DWPI 1995. 
chos productos patentados para uso tópico en productos cosméticos y dermatológicos tanto para el cuidado de la piel como del cabello. Las Labiadas, además de ser muy utilizadas con fines culinarios, también se patentan como antioxidantes y como repelentes de insectos.

Como puede constatarse, los usos de especies con técnicas de ingeniería genética que divulgan material genético y los usos sin técnicas de ingeniería que no divulgan en la solicitud ningún material hereditario tienen una consideración diferente y son clasificados de distinta forma por las Oficinas de Patentes. En cambio, esta diferencia no parece que se tenga en cuenta en el Convenio sobre Diversidad Biológica $(C D B)$, cuya redacción entendida tal cual, eximiría de las obligaciones del artículo 15 a muchas actividades de bioprospección que dan beneficios pero que no utilizan el material genético.

Sin embargo, muchos países, Partes del $C D B$, han desarrollado legislaciones que no dejan lugar a interpretación para cubrir esta laguna. Así, las legislaciones nacionales de Acceso que han promulgado muchos países como Costa Rica, Panamá, la India ("The Biological Diversity ACT", 2002) incluyen los recursos biológicos, además, de los recursos genéticos en la obligación de cumplir con el Acceso y Reparto de Beneficios (ABS).

También en la legislación de países africanos, lo importante es el acceso a los recursos biológicos.

OAU MODEL LAW, ALGERIA, 2000 - Rights of Communities, Farmers, Breeders and Access to Biological Resources

\section{AFRICAN MODEL LEGISLATION FOR THE PROTECTION OF THE RIGHTS OF LOCAL COMMUNITIES, FARMERS AND BREEDERS, AND FOR THE REGULATION OF ACCESS TO BIOLOGICAL RESOURCES}

\section{PART III \\ ACCESS TO BIOLOGICAL RESOURCES}

Application
for access to
biological
resources
and to the
knowledge
and
technologies
of local
communities

3.

) Any access to any biological resources and knowledge or technologies of local communities in any part of the country shall be subject to an application for the necessary prior informed consent and written permit.

2) Any access to any biological resource in a protected area shall be subject to an application for the necessary prior informed consent and written permit.

3) All applications for the necessary consent and written permit to access any biological resource, community knowledge or technology, shall be directed to the National Competent Authority unless otherwise explicitly provided for by law. 
Pero para los usuarios de países industrializados, les resulta paradójico que en la referencia internacional, que es el Convenio sobre Diversidad Biológica, no se incluyan los extractos biológicos de partes de organismos. De hecho el tema de las definiciones es un tema abierto en las negociaciones del Régimen Internacional de Acceso y Reparto de Beneficios, que aún está en plena discusión.

Otro punto muy importante, y también en pleno debate, es la cuestión de las definiciones de las moléculas o compuestos obtenidos de los extractos biológicos, si se van a considerar productos o derivados y su posible inclusión en el Régimen Internacional.

\section{DIVULGACIÓN DEL PAÍS DE ORIGEN EN LAS SOLICITUDES DE PATENTE}

El primer punto que se empezó a debatir para asegurar el apoyo del sistema de patentes al $C D B$ fue el de la divulgación del país de origen en las solicitudes de patentes cuando la invención se basa en una especie.

Este tema surgió en el primer SBSTTA del CDB celebrado en París, en 1995, y desde entonces se ha extendido a distintos foros como OMPI y OMC.

Se ha comprobado que era práctica habitual entre los solicitantes de patentes mencionar el país de origen. Se encontraron patentes solicitadas veinte años antes de la entrada en vigor del CDB que hacían mención al país de origen ${ }^{10}$.

* US 3773931 (A GROEBEL)

Patente americana que se refiere a una sustancia activa con propiedades hipotensoras. Esta sustancia se aisla de una planta que procede de Madagascar.

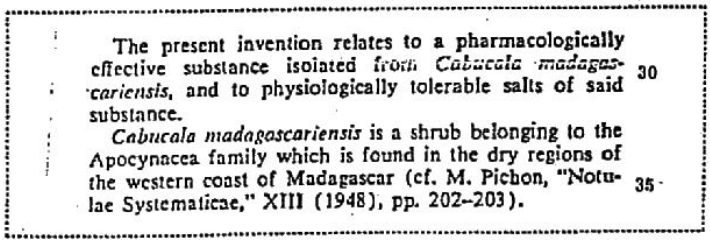

Esta patente US 3773931, publicada el 20.11.1973, utiliza una sustancia que se aísla de una planta y hace mención en la descripción la familia y las zonas de Madagascar donde se encuentra la especie endémica (Cabucala madagascariensis).

10 Asha Sukhwani: “Patentes que se refieren a material biológico (I) y Mención del país de origen en patentes relativas a material biológico (II)", publicada por el Convenio sobre Diversidad Biológica como UNEP/CBD/COP/4/Inf. 30 y por la Organización Mundial de la Propiedad Intelectual (OMPI) como WIPO/GR$\mathrm{TKF} / \mathrm{IC} / 2 / 15$. 
Se encuentran muchos casos como éste, por ejemplo, en la patente francesa (FR 1578711) que utilizan el Prunus africana del sur y este de África o una solicitud europea (EP0513671) de la empresa italiana Indena que utiliza la Commiphora mukul, citando en descripción que es endémica de la península de la India.

A pesar de esta práctica habitual sigue siendo un tema de debate la inclusión del requisito de divulgación en las solicitudes de patente como obligatorio. De hecho, la OMPI firmó un "Memorándum de Entendimiento" con el CDB y preparó un "Estudio Técnico sobre la Divulgación del Origen en las solicitudes de patente”.

La Unión Europea está a favor y ya cuatro países, Dinamarca, Suecia, Alemania y Bélgica, han introducido cambios en sus legislaciones para incluir esta obligación. Los países europeos consideran que la OMPI es el foro adecuado para llevar a cabo esos debates.

Algunos países megabiodiversos consideran que la divulgación es sólo un primer paso, pero no suficiente para el apoyo que se espera del sistema de patentes. Consideran que las Oficinas de Patentes deben apoyar al $C D B$ controlando si se ha cumplido con el PIC y el MAT para solicitudes que han utilizado recursos biológicos y consideran que la OMC es el foro adecuado para debatir la cuestión de divulgación"11.

\section{Artículo 29bis}

\section{Divulgación del origen de los recursos biológicos y/o los conocimientos tradicionales conexos}

1. A efectos de establecer una relación de mutuo apoyo entre el presente Acuerdo y el Convenio sobre la Diversidad Biológica, los Miembros, en el cumplimiento de sus obligaciones, tendrán en cuenta los objetivos y principios del presente Acuerdo y los objetivos del Convenio sobre la Diversidad Biológica.

2. En caso de que la materia objeto de una solicitud de patente concierna a recursos biológicos y/o conocimientos tradicionales conexos, se derive de ellos o se desarrolle a partir de ellos, los Miembros exigirán a los solicitantes que revelen el nombre del país que suministra los recursos y/o los conocimientos tradicionales conexos, la persona de quién se obtuvieron en el pais proveedor y, cuando se pueda conocer tras una investigación razonable, el pais de origen. Los Miembros exigirán asimismo que los solicitantes proporcionen información, con inclusión de pruebas del cumplimiento de las prescripciones jurídicas aplicables en el país proveedor al consentimiento fundamentado previo para el acceso y la distribución justa y equitativa de los beneficios derivados de la utilización comercial o de otro tipo de dichos recursos y/o conocimientos tradicionales conexos.

Posteriormente, en 2008, estos países han llevado a un acuerdo con la Unión Europea para defender una postura común en cuanto a la divulgación del país de origen siempre que se utilice el término recursos genéticos ${ }^{12}$.

11 Comunicación de Brasil, China, India, Pakistán, Perú, Tailandia y Tanzania en la OMC para incluir un nuevo Artículo 29bis en el PCT (WT/GC/W/564/Rev.1 y TN/C/W/41/Rev.1) de 6 de junio de 2006.

12 En el documento $\mathrm{TN} / \mathrm{C} / \mathrm{W} / 52$ de 19 de julio de 2008 se recoge la comunicación de éstos países a los que se ha sumado la Unión Europea, Albania, Macedonia, Islandia, Liechtenstein, Kirguisa, Sri Lanka, Suiza, Turquía y el Grupo Africano, sobre divulgación en el marco del Acuerdo de los $A D P I C$ y del $C D B$. 
Divulgación en el marco del Acuerdo sobre los ADPIC y del CDB: Proyecto de texto de modalidades

4. Los Miembros convienen en modificar el Acuerdo sobre los ADPIC para incluir un requisito de divulgación obligatoria del país que aporta/la fuente de los recursos genéticos y/o los conocimientos tradicionales asociados, cuya definición se acordará, en las solicitudes de patentes. No se tramitarán las solicitudes de patentes que no cumplan el requisito de divulgación.

5. Los Miembros convienen en definir la naturaleza y el alcance de una referencia al consentimiento fundamentado previo y el acceso y la participación en los beneficios.

6. Se entablarán negociaciones basadas en textos, en reuniones del Consejo de los ADPIC en Sesión Extraordinaria y como parte integrante del todo único, para poner en aplicación lo expuesto supra. También podrán plantearse elementos adicionales que figuren en las propuestas de los Miembros, como el consentimiento fundamentado previo y el acceso y la participación en los beneficios como parte integrante del requisito de divulgación y las sanciones posteriores a la concesión, que se tomarán en consideración en estas negociaciones.

El Régimen Internacional considera como una de las opciones crear un "Certificado de Origen" para un recurso que salga del país de origen y que viaje con él como un pasaporte. El Grupo de Expertos en Certificado estableció puntos de Control para comprobar el certificado, como son las fronteras, las Oficinas de Patentes y los Registros Comerciales. Las fronteras se han descartado como punto de control, puesto que, en la mayoría de los casos, el paso por frontera de recursos es con fines científicos y académicos.

Pero, por otra parte, los países industrializados defienden no aumentar la carga de trabajo para las Oficinas de Patentes haciendo controles de PIC, MAT y Certificados de Origen.

\section{COSTES DE COMERCIALIZACIÓN}

Según datos de la OMPI, sólo del 5 al 10\% de las patentes que se solicitan llegan a término de comercializar un producto nuevo.

Las razones pueden ser muy diferentes: los años que se requieren para desarrollar un producto nuevo, la inversión necesaria, los registros de sanidad obligatorios para comercializar productos nuevos antes de salir al mercado. Esto es especialmente largo y costoso para el sector farmacéutico, aunque menos en los otros sectores (Kerry ten Kate, 2004).

Se sabe que la investigación y desarrollo de nuevos fármacos de origen natural 262 es altamente costosa y requiere varios años de dedicación. Además, de 10.000 
muestras estudiadas, tal vez, sólo una pueda dar lugar un producto que se pueda comercializar ${ }^{13}$.

\section{DURATION AND COST OF RESEARCH}

\begin{tabular}{|l|c|c|}
\hline $\begin{array}{l}\text { Sector } \\
\text { Source: ten Kate and Laird, 1999 }\end{array}$ & $\begin{array}{c}\text { Years to } \\
\text { develop }\end{array}$ & $\begin{array}{c}\text { Cost } \\
\text { (USSm) }\end{array}$ \\
\hline Pharmaceuticals & $10-15+$ & $231-500$ \\
\hline Botanical medicines & $<2-5$ & $0.15-7$ \\
\hline Personal care and cosmetics & $<2-5$ & $0.15-7$ \\
\hline Commercial agricultural seed & $8-14$ & $\begin{array}{l}\text { trad: } 1-2.5 \\
\text { GMO:35-80 }\end{array}$ \\
\hline Ornamental horticultural produce & $1-20+$ & $0.05-5$ \\
\hline $\begin{array}{c}\text { Crop protection - biocontrol agent } \\
\text { chemical pesticide }\end{array}$ & $2-5$ & $\begin{array}{c}1-5 \\
40-100\end{array}$ \\
\hline Industrial enzymes & $2-5$ & $2-20$ \\
\hline
\end{tabular}

(9) Kerry ten Kate, 2004

Pero además, los países occidentales tienen un protocolo férreo para comercializar productos nuevos, especialmente, los nuevos medicamentos que requieren varias fases de ensayos clínicos (fases I, II, III, IV), con suministro creciente de muestras y ensayos doble ciego en hospitales.

De cualquier forma, la Unión Europea tiene una legislación más estricta para los fármacos naturales que los asimila a los sintéticos, frente a Estados Unidos en el que algunos pueden pasar como suplementos alimenticios.

Se tardan muchos años en conseguir beneficios y los costes son tan elevados, que para los detentores iniciales de las especies y de los conocimientos tradicionales, el retorno puede ser a muy largo plazo.

\section{CONOCIMIENTOS TRADICIONALES}

Las “Leyes de Patente" requieren al solicitante hacer mención al estado de la técnica anterior. Esto es interpretado, en el caso de patentes relacionadas con la biodiversidad, como la obligación de mencionar si han utilizado conocimientos tradicionales, si bien, esta obligación no está explícita en dichas leyes.

13 Kerry ten Kate: “Biopiracy or Green Petroleum? Expectations \& Best Practices in Bioprospecting", 1995. 
En el seno de OMPI se creó en 2001 un Comité Intergubernamental donde se debaten los temas de Propiedad Intelectual, Recursos Genéticos y Conocimientos Tradicionales, que ya se ha celebrados catorce sesiones.

Para el caso de Conocimientos Tradicionales se ha llegado a debatir sobre una "protección positiva" o sobre una "protección defensiva".

- La protección positiva para proteger estos conocimientos per se. Los países en desarrollo han propuesto que sean por sistemas sui generis, específicos para estos conocimientos. La falta de apoyo de los países industrializados no ha permitido llegar a adoptar estos sistemas.

- La protección defensiva para no conceder solicitudes por falta de novedad si la invención se ha basado en conocimientos tradicionales.

OMPI ORGANIZACIÓN MUNDIAL DE LA PROPIEDAD INTELECTUAL
WIPO/GRTKF/IC/10/5

ORIGINAL: Inglés

FECHA: 2 de octubre de 2006

\section{$\mathbf{S}$}

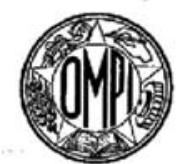

$\mathrm{s}$

COMITÉ INTERGUBERNAMENTAL SOBRE PROPIEDAD INTELECTUAL Y RECURSOS GENÉTICOS, CONOCIMIENTOS TRADICIONALES Y FOLCLORE

Décima sesión

Ginebra, 30 de noviembre a 8 de diciembre de 2006

LA PROTECCIÓN DE LOS CONOCIMIENTOS TRADICIONALES: PROYECTO DE OBJETIVOS Y PRINCIPIOS

Iberoamérica no tienen documentados estos conocimientos que se transmiten de

Para la protección defensiva, se ha estudiado facilitar la labor del "Examinador de Patentes" de este sector aumentando las bases de datos y publicaciones especializadas en estos conocimientos.

La creación de bases de datos ha resultado ser muy problemática. Los países de forma oral entre chamanes de tribus, de una generación a otra. Algo parecido sucede 
en África. El problema está en que las bases de datos podría divulgar conocimientos secretos y, actualmente, no protegidos.

En cambio en Asia, países como China, que conoce el uso de casi cinco mil plantas medicinales, y la India, que los tiene documentados en la medicina ayurvédica que se enseña en Universidades, no han tenido inconveniente en crear bases de datos para facilitar la labor de examinadores de patente y dejarlos disponibles en el portal de OMPI (ver Tabla 1, página 255).

En 2008, el tema del debate en OMPI fue las definiciones de "Conocimiento Tradicional” y de "apropiación indebida”, que también se discute en el CDB.

En junio de 2009, el Grupo Africano presentó una propuesta sobre "Elementos de un nuevo Mandato" de este Comité para elaborar instrumento(s) jurídicamente vinculante(s) sobre recursos genéticos, conocimientos tradicionales y expresiones culturales tradicionales y celebrar una Conferencia Diplomática en 2011 para adoptar estos instrumentos ${ }^{14}$.

Esta propuesta sorprendió a los países industrializados que no están a favor de adoptar instrumentos vinculantes en este foro. Por ello, no se llegó a ningún acuerdo del programa de trabajo futuro de este Comité.

\section{CONSIDERACIONES FINALES}

En el seno del CDB se está negociando un Régimen Internacional de Acceso y Reparto de Beneficios (ABS) que podría tener elementos vinculantes. Los países megabiodiversos piden que tenga rango de protocolo.

Sería esencial ver, a fines de claridad de la legislación aplicable, cómo se consideran las definiciones de "recursos biológicos", "productos y derivados" sobre todo, tras actividades de bioprospeción, y en relación con extracciones de muestras biológicas para obtener metabolitos secundarios con fines de explotación comercial y que no contienen material de herencia.

Desde la entrada en vigor del $C D B$, el tema de divulgación del origen en las solicitudes de patente, ha avanzado algo en catorce años y, sin embargo, parece poco avance teniendo en cuenta que ya era práctica habitual del solicitante de patente divulgar el país de origen del recurso.

Más importante son el PIC y el MAT, y los puntos de control, y en esto no se ha avanzado. Los países industrializados consideran que las Oficinas de Patente

14 El documento WIPO/GRTKF/IC/14/8.Rev. recoge la propuesta del Grupo Africano, http://www. wipo.org. 
no se deben sobrecargar y sus competencias nada tienen que ver con los objetivos del $C D B$.

Otro punto importante de control serían los Registros Comerciales, como son los Registros de Sanidad, pero todavía no se sabe si se les va a involucrar en este control.

Es poco realista creer que la bioprospección pueda ser el incentivo principal para la conservación de la biodiversidad o para generar beneficios a corto plazo, dado los costes y tiempo que requiere la comercialización de productos. Por ello, sería muy interesante que fueran los proveedores los que solicitaran las patentes, comercializaran y distribuyeran los productos a nivel mundial o en colaboración con empresas usuarias de dichos productos.

Estos proveedores serían los primeros interesados en invertir parte de los beneficios en la conservación de la biodiversidad.

Para las comunidades indígenas que pueden ser proveedores iniciales de recursos y de conocimientos tradicionales asociados, el poder introducirse en el mercado occidental por sus propios medios resulta una tarea titánica, sobre todos para productos con fines médicos. Con el apoyo de las empresas de sus propios países proveedores, de sus Universidades o de sus Oficinas de Patentes, podría ser más factible entrar en el mercado. Tampoco son de descartar otras opciones como ser cotitulares de patentes, asociados y apoyados por empresas de países usuarios, o con programas de apoyo como la "Iniciativa Biotrade" (Biocomercio) de la UNCTAD.

En cualquier caso, aunque no se soliciten patentes, no hay que olvidar que las patentes son fuente de información tecnológica y pueden proporcionar gran cantidad de información desde depuración de agua, biorremediación, monitorización de vida salvaje, evaluación de la salud de un ecosistema, así como conocer el uso de la biodiversidad, o de la elaboración de medicamentos, cosméticos, etc. Y que esta Información es muy útil y está asequible por Internet. Gracias a esta información se puede preparar mejor la transferencia de tecnologías que ayuden y hagan posible la conservación y el uso de la biodiversidad.

Las posibilidades del sistema de patente relacionado con los recursos son múltiples y, como se ha dicho reiteradamente, el problema de los recursos biológicos y genéticos requiere una solución multilateral y global y siempre teniendo en cuenta todas las posibilidades de utilización de la biodiversidad así como la necesidad de su conservación. 
Respuestas A

da

LA PÉRDIDA DE BIODIVERSIDAD 
